\title{
Influences of task concreteness upon transitive responding in humans
}

\begin{abstract}
The derivation of the conclusion "Anna is bigger than Mary" from the premises "Anna is bigger than Paul" and "Mary is smaller than Paul" is considered an instance of transitive deduction. For a non-verbal presentation, the premise statements were here transformed into a multiple operant discrimination task. Adult subjects were trained with overlapping pairs of a six-member stimulus series $(\mathrm{A}+\mathrm{B}-, \mathrm{A}+\mathrm{C}-, \mathrm{C}+\mathrm{D}-, \mathrm{D}+\mathrm{E}-, \mathrm{E}+\mathrm{F}-;+$ : choice rewarded, -: choice penalized). A computer game-type presentation that hid the actual problem structure from the subjects was employed. The effects of varying the presentation style of the task on the objective performance and the structure awareness of subjects were investigated. A first experiment used random polygons as stimuli and the relations between them were only signalled by the above reinforcement allocations. In a second experiment the stimuli were cartoon figures additionally involved in a dominance hierarchy that was suggested graphically. A third experiment used named items that were related through visible size differences in addition to the reinforcement allocations but was otherwise like an experiment using an abstract format reported by Werner et al. (1992). In all experiments a similar proportion of subjects responded transitively when subsequently tested with the pairs $\mathrm{BD}, \mathrm{BE}$ and $\mathrm{CE}$ by preferentially choosing stimulus $\mathrm{B}$ or $\mathrm{C}$. Each subject subsequently filled in a questionnaire, completed a stimulus ordering exercise, and was interviewed to find out whether they were explicitly aware of the stimulus hierarchy underlying each of the tasks. Although the proportion of subjects revealing an explicit transitive responding increased together with the concreteness of the stimuli and their relations across the experiments, the objective performance in terms of choice accuracy did not vary. The accuracy performance on tests could be accurately simulated with a modification of a simple conditioning model. It is concluded that an
\end{abstract}

M. Siemann ( ) J. D. Delius

Allgemeine Psychologie, Universität Konstanz, D-78434 Konstanz, Germany implicit mode of processing may underlie many instances of transitive responding in humans even when explicit task understanding is reported.

\section{Introduction}

The capacity to derive the relation "Anna is bigger than Mary" from the premises "Anna is bigger than Paul" and "Mary is smaller than Paul" involves a transitive-inference competence. The answer to the question "Who is bigger, Anna or Mary?" presents little difficulty to adults, but Piaget (1921) was of the opinion that only children older than 7 or 8 years - that is, those who had reached the concrete-operational stage, were capable of this cognitive feat. This observation led to a number of studies that attempted to identify the causes of this deductive deficit. It turned out that the inability of younger children to solve this type of problem was due less to logical incapacity than to their inability to remember the premises correctly (Bryant \& Trabasso, 1971). This realization, and a mounting interest in the cognitive capabilities of animals, led to the development of a fully non-verbal form of task presentation (McGonigle \& Chalmers, 1977, 1992). For this purpose the verbal premises are turned into operant discrimination tasks. Instead of the premises $\mathrm{A}>\mathrm{B}, \mathrm{B}>\mathrm{C}, \mathrm{C}>\mathrm{D}, \mathrm{D}>\mathrm{E}$, subjects are instructed with the item pairs $A+B-, B+C-$, $\mathrm{C}+\mathrm{D}-, \mathrm{D}+\mathrm{E}-$, where $\mathrm{a}+$ signifies a reward and a - means a penalty following the choice of the corresponding stimulus. When the performance on these pairs of premises is quite accurate, tests are introduced in which the items B and D are offered simultaneously. Transitive responding is given when stimulus B (nearer to the positive end of the series) is preferred over D. With this kind of task it was shown that pigeons (Fersen, Wynne, Delius, \& Staddon, 1991; Siemann, 1993b, Siemann, Delius \& Wright, 1996), rats (Davis 1992), squirrel monkeys (McGonigle and Chalmers, 1977; 1992), chimpanzees (Boysen, Berntson, Shreyer, \& Quigley, 1993; Gillan, 1981), six-year-old children (Chalmers \& McGonigle, 1984; Mühlherr \& Siemann, 1996), and adult humans (Siemann, $1993 \mathrm{a}, \mathrm{b}, 1994 \mathrm{a}, \mathrm{b}$; Siemann \& Delius, 1993; Werner et al. 1992) can behave transitively. 
To avoid confusion it is worthwhile distinguishing this transitive responding task from a transitive-equivalence problem which has also been extensively studied (Sidman, 1990). Suppose that a person learns that the Spanish word si is equivalent to the English yes, and in turn that the word yes is equivalent to the French oui. From this he or she can be expected to deduce that $s i$ is equivalent to oui. This kind of inference problem has also been transformed into a conditioning task suitable for comparative research (Kuno, Kitadate, \& Iwamoto, 1994; McIntire, Cleary, \& Thompson, 1987). Minimally it involves an organism learning to choose a stimulus $B$ only when it is preceded by a stimulus $\mathrm{A}(\mathrm{A} \rightarrow \mathrm{B}+, \mathrm{X} \rightarrow \mathrm{B}-$, where $\mathrm{X}$ stands collectively for other stimuli involved in other matching pairings not detailed here) and analogously, to choose $\mathrm{C}$ only after having it presented following $\mathrm{B}(\mathrm{B} \rightarrow \mathrm{C}+, \mathrm{X} \rightarrow \mathrm{C}-)$. It is then tested by being presented with sequences $A \rightarrow C$ and $X \rightarrow C$. The organism is said to behave transitively if it responds preferentially to $\mathrm{C}$ when it is preceded by $\mathrm{A}$. This corresponds to a relational structure $\mathrm{A} \equiv \mathrm{B} \equiv \mathrm{C}$ allowing the conclusion $\mathrm{A} \equiv \mathrm{C}$. However, apart from a common concern about the role of verbal mediation when humans deal with the same kind of task (Bentall, Dickins, \& Fox, 1993), there is no evidence to suggest any profound link between the equivalence problem and the inference task occupying us here.

Historically, research into human cognitive processes began by using the method of introspection or self-report. Subjects described their thoughts, impressions, and strategies verbally while, or after, solving a given problem. Partly as a consequence of this research strategy many cognitive abilities were considered to be dependent on verbalization and to be connected with awareness. However, over the last decade, evidence has accumulated that suggests that many cognitive feats may be achieved implicitly - that is, dissociated from any verbalizable awareness of the underlying structure that in principle would seem essential for the successful solution of the tasks at hand (see, e.g., Haan, Young, \& Newcombe, 1987; Reber, 1989; Seeger, 1994; Schacter, 1987). In a study on transitive responding, for example Werner et al. (1992) reported that some human adults who had behaved transitively in test trials were not capable of explaining afterwards why or how they had done so. However, this could have been due to the fact that in their experiment both the stimulus items were totally abstract and the inequality relations between them were indistinct.

We now report three experiments that explore this issue by systematically varying the concreteness of the items and the obviousness of their relations. All three experiments, much as that of Werner et al. (1992) were conceived as part of a single research effort and administered to subjects successively drawn from the same population of university students. The experiments involved inequality series consisting of six items presented within five overlapping item pairs serving as premises. These premises were embedded in computer-game-like procedures that were meant to deflect the subjects from an easy identification of the experiment's true purpose. All the items used were visual stimuli and in all the experiments relations were established between them through a symbolic monetary reward or a penalty according to an allocation scheme analogous to that described above. In Experiment 1 (briefly reported by Siemann \& Delius, 1993), the stimuli were abstract random polygons and the relations between them were only signalled by differential reinforcement allocations. Experiment 2 used cartoon figures as stimuli, but the inequality relations among them were also conveyed by pictorially suggested dominance relationships. Experiment $3 \mathrm{em}-$ ployed cartoon figures with names written on them and related to each other through clearly visible size differences in addition to the reinforcement inequalities. By involving two separate series of items instead of one, it bore similarity with the experiment of Werner et al. (1992). These authors, however, had used decorative-geometric shapes instead of named person-like figures and a bare conditioning format instead of a personalized game presentation. After the subjects had completed the relevant tasks, they were required to fill in a formal questionnaire, asked to arrange cards bearing the relevant stimuli, and subjected to an investigative interview. These procedures were intended to elicit, without leading, whatever declarative knowledge the subjects had about the deeper structure of the procedure they had participated in and to find out whether, independently of such awareness, they could transfer some knowhow to a different, but related, task.

Our expectation was that the proportion of subjects capable of verbally reporting correct knowledge about the logical structure of the tasks and about the solution strategies they had used would increase from Experiment 1, to Experiment 2 and from Werner et al.'s (1992) experiment to our Experiment 3 because of the increased concreteness of the tasks used in these latter experiments. But perhaps an equally, or even more interesting, question was whether the objective performance (test speed and accuracy) would improve with the presumed increase in awareness about the task's true nature. A marked dependance of the performance quality on the surface formats of tasks has, for example, been well documented for bayesian and deductive reasoning problems (e.g. Gigerenzer \& Hoffrage, 1995; Sperber, Cara, \& Girotto, 1995). We were also interested in examining whether a learning-theory model proposed previously (Luce, 1959; Werner et al., 1992; Wynne, Fersen, \& Staddon, 1992) would continue to provide an adequate account of transitivity-test results when the deduction task was posed in a more concrete form. If it did so, this would strengthen the argument that, regardless of differences in problem awareness, one single process might be involved in generating the objective transitive performances.

\section{Experiment 1}

Abstract visual stimuli

In this experiment the stimuli forming the premise pairs were random, irregular polygons and the inequalities between them were conveyed exclusively by the fact that the 
choice of one led to a symbolic monetary gain, whereas the choice of the other led to a symbolic monetary loss. When subjects had learned to achieve criterion accuracy with the premise pairs, they had to choose, without being given any feedback, between the same stimuli offered in novel test pairs.

\section{Method}

Twenty-four students ( 12 females, 12 males, mean age 23 years) were trained with overlapping stimulus pairs of a six-member series in which the individual stimuli were 12-sided random polygons (Attneave, 1956). The presentation of the stimuli was implemented on a computer monitor in the form of a game. The subjects' task was to lead a figure through a fantasy castle choosing among pairs of doors
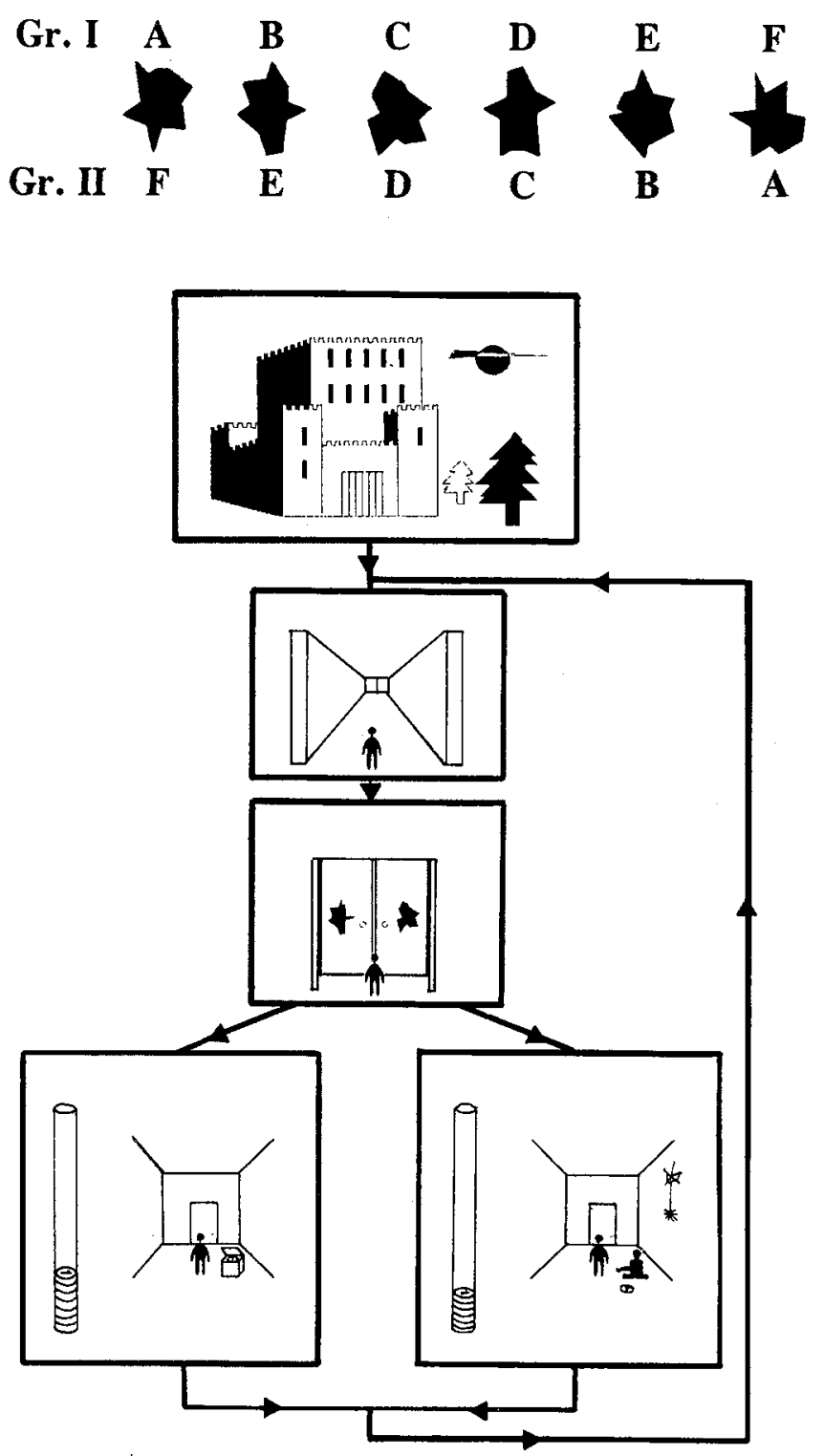

Fig. 1 Computer game and stimuli used in Experiment 1. If, during training trials, the subject chose the door bearing the correct stimulus, a coin was added to the coin pile; otherwise a coin was lost to a beggar (modified from Siemann, 1994 b) bearing the stimuli by pressing the left or right pointing cursor keys of a personal computer. Each door bore one stimulus of a pair (Figure 1). The stimuli were $5 \mathrm{~cm}$ apart and about $2.5 \times 2 \mathrm{~cm}$ in size. The allocation of positive and negative symbols to the left or to the right door varied from trial to trial according to quasi-random sequences (Gellermann, 1933). Correct choices led to a treasure chamber and winning a coin, accompanied by an ascending two-tone sequence (4s). Wrong choices led to a dungeon with a beggar and the loss of a coin, accompanied by a descending multi-tone sequence $(10 \mathrm{~s})$. In trials with no feedback, the figure entered an empty passage. The subjects were trained with the pairs $\mathrm{A}+\mathrm{B}-, \mathrm{B}+\mathrm{C}-, \mathrm{C}+\mathrm{D}-, \mathrm{D}+\mathrm{D}-, \mathrm{E}+\mathrm{F}-$. The correspondence of the stimuli to the letter denominations was counterarranged for two groups of 12 subjects, as is indicated in Fig. 1, top. This was meant to counteract any spontaneous preferences for particular stimuli. Since ultimately there were no significant differences between these two groups, their results are henceforth pooled.

To facilitate learning, the training pairs were presented in runs of 8 , 4 , or 2 during the first 240 trials. From the 241 st trial onwards the pairs were shown in quasi-random sequences. On a random sixth of the trials there was no feedback. When the subjects achieved a criterion of less than $30 \%$ errors with each of the training pairs within a learning block ( 60 trials; binomial test, $p<.01$ ), a test phase began. The test phase consisted of a total of 130 trials, the three test pairs $\mathrm{BD}, \mathrm{BE}$, and $\mathrm{CE}$ each being presented 10 times and the training pairs each 20 times. The test pairs were not reinforced, the proportion of trials with no feedback thus being $23 \%$. For each trial the choice-reaction time, measured from the onset of the stimuli on the monitor until the subject's choice, as well the correctness of the choice, was recorded.

Before the experimental session began, the subjects were given written instructions on the monitor that out of a given pair they had to choose the stimulus that yielded a coin. They were told which keys to use and about the missing reinforcement in some trials. But they were not told about the true purpose of the experiment.

After each subject had completed the experiment, they were questioned thoroughly as to whether they could transfer knowledge about the hierarchical item sequence underlying the task into a verbal report and into a sequencing assignment. First, they were required to fill in a free report-style questionnaire that asked what they thought the purpose of the experiment had been, how they had managed to learn the training pairs, how they had endeavoured to solve the novel test pairs, and whether they could reproduce the training pairs, either by drawing or by describing them. Then they were given six cards bearing the stimuli used, and were asked to lay them out in any order their experimental experience suggested to them. These subjects who could not do so and declared not to know what was expected of them, were then enticed nevertheless to try. These procedures represented indirect investigations into the subjects' knowledge of the stimulus hierarchy underlying the task and the extent to which they could transfer any information about it to a modified, but analogous, task. Afterwards, subjects were directly interviewed about whether they had identified the item hierarchy. Those who did not produce answers to that effect were shown the correct sequence with the cards and asked whether they had recognized it during the experiment. If they reported that they had not, they were again asked about their strategies in responding to the novel-test pairs. Finally, they were told the true purpose of the experiment; any relevant remarks they volunteered after this were noted.

\section{Results}

The subjects required between 300 and 840 trials (mean $395)$ to achieve the learning criterion. The results of the test phase are shown in Figure 2. The reaction times and error rates for the training pairs follow a similar inverted U-shaped trend, a result frequently occurring with transitive-inference tasks - known as the symbolic position effect. End pairs containing non-ambivalent stimuli were solved more accurately than pairs consisting of the middle 


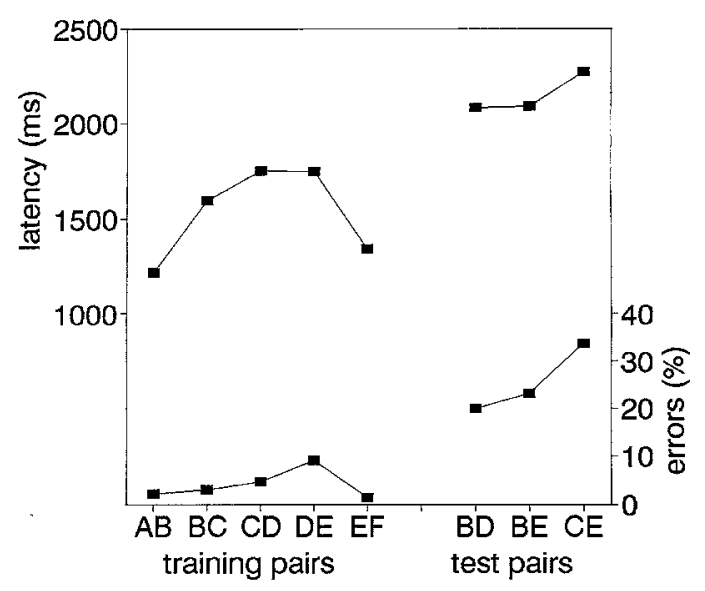

Fig. 2 Mean latencies and error rates for training (right) and test pairs (left) during the test phase $(n=24)$ in Exp. 1

stimuli. The error rates for the three test pairs were well below the $50 \%$ chance level (Fig. $2 ; t$ tests; BD: $t_{23}=4.52$, $p<.001$; BE: $t_{23}=4.32, p<.001$; CE: $t_{23}=2.05, p=.06$ ). Test pairs $\mathrm{BD}$ and $\mathrm{BE}$ yielded fewer errors and faster responses than did $\mathrm{CE}$.

Further analysis revealed that nine subjects made more than $30 \%$ errors when confronted with the test pairs. In fact, each of these non-solver subjects chose at chance level or below (binomial tests, $p>.05$ ). Fifteen subjects, however, solved the test pairs, producing less than $30 \%$ errors, each of them thus performing significantly better than chance (binomial tests, $p<.05$ ). Analysis of the post-sessionenquiry responses showed that these test solvers were not a homogeneous group. Eight subjects stated unequivocally in the questionnaire that they had recognized the item hierarchy in the course of the session ("stimulus order", "item sequence", "polygon hierarchy"). They also declared that they had dealt with the test pairs in conformity with this hierarchy. The same subjects confirmed having used this strategy during the interview. Accordingly these eight subjects were classed as explicit solvers. With one exception, these subjects also laid out the cards in the correct order without any hesitation or prompting.

The other seven test solvers produced no evidence whatever of having identified the item hierarchy. In the questionnaire they reported that they had dealt with the test pairs with random choices without applying any strategy, that they had not found a solution for these pairs ("I chose according to trial and error"), or they reported strategies they could not properly explain ("I used the previous experience with the combinations"). None of these subjects declared having recognized the hierarchical structure when directly asked in the interview. These subjects were categorized as implicit solvers. They were all puzzled by the card-laying task, most of them asking either which order was meant or wondering how to lay out all item pairs with only six cards. But when the experimenter insisted, and after some trying, five of them produced the correct card sequence. They persisted, however, in saying that they

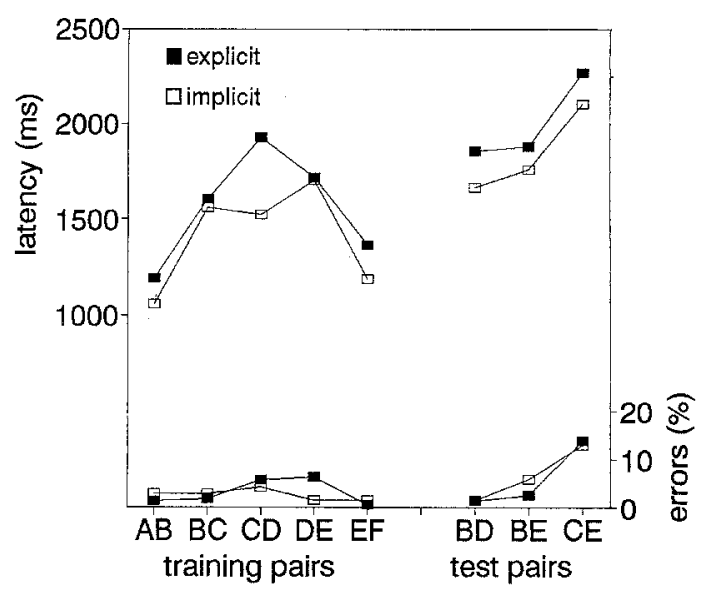

Fig. 3 Mean latencies and error rates for training (left) and test (right) pairs in the test phase for implicit $(n=7)$ and explicit $(n=8)$ solvers, Exp. 1

could not relate the sequence to the structure of the task they had just dealt with.

The results indicate that humans can behave according to deductive rules, even when they are, as far as one can tell, not aware of doing so. Nearly half of the solvers exhibited such implicit reasoning. Remarkably, the explicit and implicit solvers yielded very similar objective speed and accuracy results with the training and test pairs (Figure 3). There were no significant differences in choice accuracy or speed between them (U tests, $n_{1}=7 ; n_{2}=8$; speed: $U=24$; accuracy: $U=24$; ps $>.05$ ).

Most of the solvers, incidentally, reported having given names to the stimuli. The names referred either to single features (e.g., "peak up," "peak down") or to holistic associations (e.g., "star," "face," "bird"). Some of these subjects declared that they had verbalized the relations between the stimuli of pairs with expressions such as " $\mathrm{X}$ beats $\mathrm{Y}$ " or " $\mathrm{X}$ is more valuable than $\mathrm{Y}$."

\section{Discussion}

The results show that transitive deduction in a non-verbal task does not necessarily depend on knowledge that is consciously available or verbally describable. Almost half of the test solvers could not account for how they had come to choose transitively. They had obviously not become aware of a stimulus sequence and were surprised when told about the true purpose and actual structure of the experiment. Either they had no explanation of how they had coped with the test pairs, or their explanations were totally wrong. It is possible that the transitive choices of the implicit solvers were based on stimulus values that had accrued through conditioning. Conditioning models assume that throughout the learning phase the individual stimuli of a series acquire varying associative values, depending on the reward or the penalty that follows responses to them. Simulations with such models yield stimulus values that decrease stepwise from the positive to the negative end of 
the series, so that transitive choices can be explained easily. For the details of two such conditioning models and the results of simulations in the present experiment, the reader is referred to the Appendix. The fact that there was no difference in terms of accuracy or speed between subjects who implicitly and explicitly solved the task suggests that the explicit solvers also responded according to conditioned stimulus values, but that they were also aware, and capable, of verbalizing the implications of the value ordering when asked later about them in the questionnaire.

We cannot say whether the explicit solvers were already aware of the stimulus sequence during the learning phase. According to their questionnaire answers, some of them at some point translated the abstract-value dimension into some apparently concrete, but plainly only subjectively valid, stimulus dimension such as "increasing complexity" or "decreasing edginess." The placing of stimuli on some single dimension is of course a precondition for the recognition of stimulus sequences. It was striking that virtually all the explicit solvers ordered the cards correctly without hesitation. Implicit solvers often stated at first that they were not capable of arranging the cards in any specific order. Most of them, however, laid out the correct sequence when the experimenter insisted on showing that they were capable of some performance transfer. However, they were consistently surprised when told that it represented the structure underlying the computer game they had just completed. Non-solvers incidentally often only laid out card pairs and, when shown the correct hierarchy, often declared that they had confused one or more polygons or had learned the stimuli pairwise without recognition of any further relationships between them.

\section{Experiment 2}

\section{Concrete visual stimuli}

In this experiment we retained the relational structure, the non-verbal presentation, and the reinforcement allocation scheme of Experiment 1, but the stimuli used were figurine personages of a quite concrete nature, also related through pictorially suggested social dominances.

\section{Method}

Twenty students participated in the experiment (11 male, 9 female, mean age 24 years). Six different cartoon figures of equal height served as stimuli. They appeared black on a turquoise background and were set $8 \mathrm{~cm}$ apart on the monitor screen, each fitting into an imaginary $4 \times 5-\mathrm{cm}$ rectangle. The stimuli and the counterbalanced allocation scheme to two groups of 10 subjects are shown in Figure 4, top.

The task was again presented as a computer game. Each trial showed two of the figures standing face to face. When subjects chose one of the figures by pressing a right or a left key, they received two kinds of feedback. The positive dominant figure stayed put and sent the other figure off, as was suggested by a suitable speech bubble. As an apparent consequence, the negative, submissive figure moved away. Afterwards a pile of coins appeared on the screen (Figure 4). Choices of the positive stimulus led to the gain of a coin, accompanied by an ascending tone sequence. Choices of the negative figure led to the loss

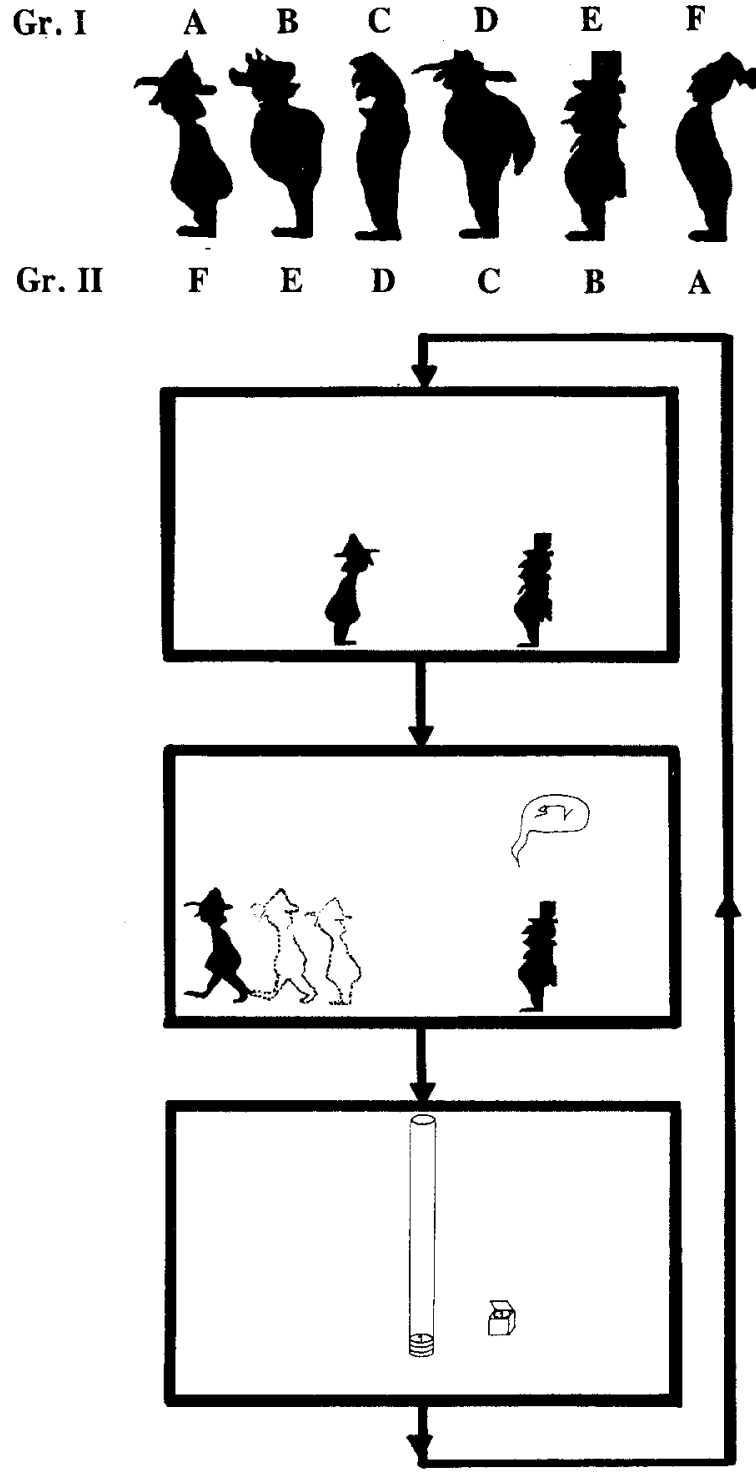

Fig. 4 Computer game and stimuli used in Exp. 2. During training trials when the subject made a choice response, the submissive figure ran away, while the dominant one stayed put. Choices of the dominant figure yielded the gain of a coin. Choices of the submissive figure led to the loss of a coin

of a coin, accompanied by a descending tone sequence. In nonreinforced trials, no animated or tone feedback was given and the coin pile was shown unchanged. The subject initiated the next trial by pressing a middle key. The experimental design, the procedure, as well as the learning criterion, were equivalent to those of Experiment 1, except that the stimuli were presented in runs for the first 120 trials only. The questionnaire, the card-laying task, and the inverview were also analogous to those used in Experiment 1.

Results

The subjects needed between 180 and 360 trials (mean 216) to reach the learning criterion. The mean performance on the training pairs during the test phase is shown in Figure 5. The reaction times and error rates for these pairs show again the inverted $\mathrm{U}$-shaped trends corresponding to the 


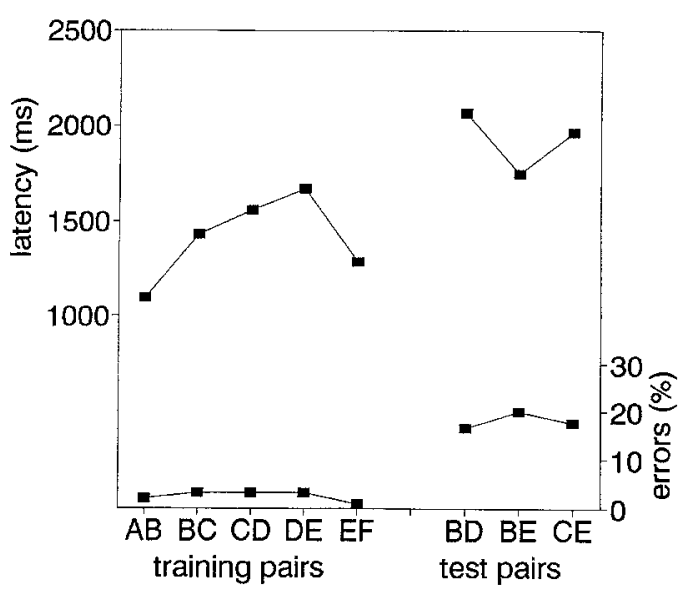

Fig. 5 Mean reaction times and error rates for training (left) and test (right) pairs during the test phase of Exp. $2(n=20)$

usual symbolic-position effect. For the reaction times the function is somewhat asymmetric, with pair DE exhibiting the longest reaction times.

The mean error rates for the three test pairs (Figure 5) are well below the $50 \%$ chance level ( $t$ tests; BD: $t_{19}=5.43$, $p<.001$; BE: $t_{19}=4.07, p<.001$; CE: $t_{19}=4.47 ; p<.001$ ). Mean reactions to pair $\mathrm{BE}$ were faster but at the same time were less accurate than those to pairs $\mathrm{BD}$ and $\mathrm{CE}$. With a single exception, the subjects reported that they gave names to the figures, either as a whole or to a certain feature. They also described relations among the figures verbally, mostly in the form of " $\mathrm{X}$ is stronger than $\mathrm{Y}$," " $\mathrm{X}$ sends $\mathrm{Y}$ away" or $\mathrm{X}$ beats $\mathrm{Y} . "$

In the same criteria as described in Experiment 1 the 15 subjects who solved the test pairs transitively at above chance level (less than 30\% errors, binomial tests, $p<.05$ ) were classified as explicit or implicit. Of these solver subjects 12 declared that they had used knowledge about the hierarchical order for the solution of these pairs, and with one exception, they unhesitatingly laid out the cards in the correct order. The remaining 3 subjects could not specify how they had dealt with the test pairs, and did not mention an item hierarchy or sequence in the questionnaire or during the interview. As in Experiment 1, these implicit solvers expressed surprise when confronted with the cardlaying task and only one of them eventually laid out the correct sequence, while still asserting uncertainty about its meaning. The choice accuracies and reaction times on learning and test pairs of the 3 implicit solvers fell within the range of those of the 12 explicit solvers.

\section{Discussion}

A larger proportion (12 out of 15) of the solver subjects than in Experiment 1 ( 8 out of 15) reported that they had been guided by an item hierarchy whilst solving the task. Their descriptions suggested that they had converted the non-verbal task into a verbal format. The figures were named, compared in strength or dominance, and ordered into a corresponding sequence. These explicit subjects, with one exception, arranged the stimulus cards in the correct sequence. However, the 3 subjects who had obviously not recognized the underlying sequence still solved the tests transitively, one of them with a perfect $100 \%$ accuracy. These implicit subjects had labelled the figures verbally, but they could only describe the relationships within pairs, not the overall hierarchical arrangement. They expressed surprise when told the purpose of the experiment and about their good test performance. One of the test non-solvers surprisingly managed to lay out the correct card sequence.

\section{Experiment 3}

\section{Verbal items and size relations}

The next question was whether a task presented in a format closer to that of a classic verbal syllogism would yield fundamentally different results, from those reported above. The design of the experiment differed somewhat from that of Experiment 1 and 2, but paralleled that of the experiment carried out by Werner et al. (1992). They had used $2 \times 6$ unnamed abstract shapes arranged in two independent premise series and a formal conditioning task presentation. We used 12 unusual names written on person-like figures as stimuli, but similarly arranged them into two separate series of six items each. As well as the relations established through the usual reinforcement allocations, the figures of given pairs differed visibly in size. The subjects were also more extensively pre-instructed about the task execution than in Werner et al.'s (1992) experiment. Apart from allowing the usual tests within each series, this doubleseries design also permitted test pairings that involved stimuli belonging to the different series. The results of such tests, as will be explained below, are of some special theoretical interest.

\section{Method}

Twenty students ( 11 female, 9 male, mean age 24 years) participated in the experiment. The critical stimuli were 12 infrequent male names, all consisting of five letters and beginning with the letter $H$. During training, the 12 names were presented in pairs arranged in two nonoverlapping series: $\mathrm{A}+\mathrm{B}-, \mathrm{B}+\mathrm{C}-, \mathrm{C}+\mathrm{D}-, \mathrm{D}+\mathrm{E}-, \mathrm{E}+\mathrm{F}-$, and $\mathrm{a}+\mathrm{b}-, \mathrm{b}+\mathrm{c}-$, $c+d-, d+e-, e+f-$. To control for any pre-existing ranking tendencies the various names were allocated according to a counterbalanced scheme to four equal groups of subjects (Figure 6, top). Since the results did not ultimately reveal any differences between the groups, they were pooled for the purposes of evaluation.

The stimuli were presented in the form of a computer game. Each trial involved the presentation of two figures that bore names on their shirts, $8 \mathrm{~cm}$ apart. The left or right position of the names varied according to quasi-random sequences (Gellermann, 1933). The legs of the figures were at first hidden behind a wall. After the subjects had chosen by pressing the left or the right pointer key, the wall was removed and the figures appeared in full size (Figure 6). The positive figure was always $11-\mathrm{cm}$ tall, the negative was always only $10-\mathrm{cm}$ high and stood on a $1-\mathrm{cm}$ pedestal. At the same time, a pile of coins was shown. The choice of the taller figure led to the gain of a coin, accompanied by an ascending tone sequence; the selection of the 


\begin{tabular}{|llllllllll|}
\hline Gr. & I & II & III & IV & Gr. & I & II & III & IV \\
\hline Helge & A & F & A & F & Hardy & a & f & f & a \\
Hasko & B & E & B & E & Henno & b & e & e & b \\
Horan & C & D & C & D & Hagen & c & d & d & c \\
Hiass & D & C & D & C & Holdo & d & c & c & d \\
Haymo & E & B & E & B & Herms & e & b & b & e \\
Heink & F & A & F & A & Hippo & f & a & a & f \\
\hline
\end{tabular}

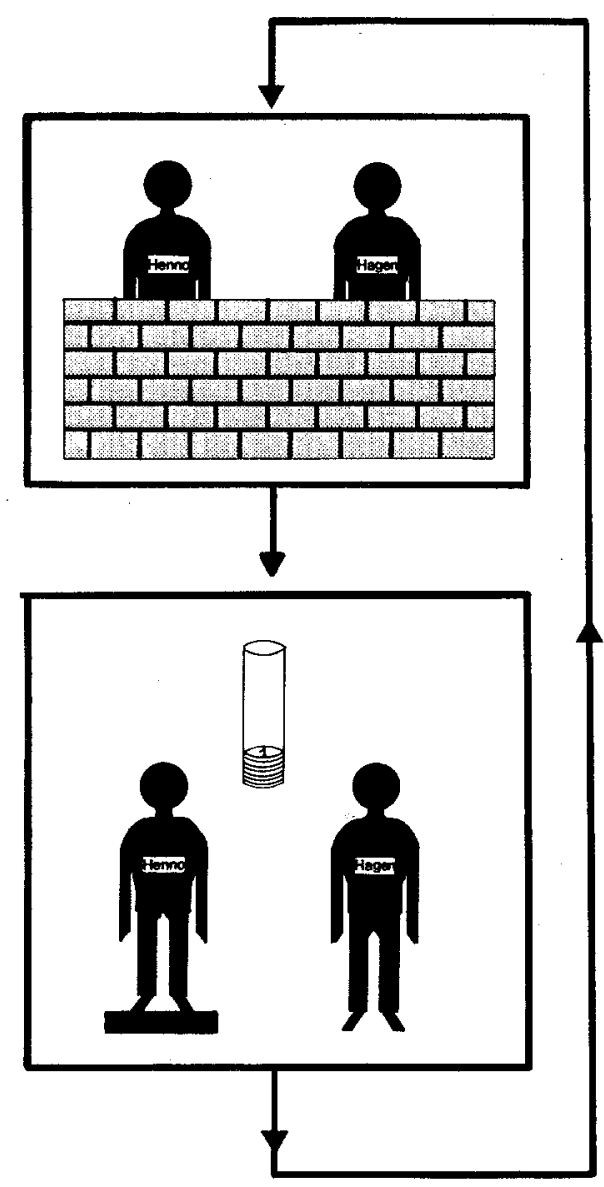

Fig. 6 Computer game and stimuli used for Exp. 3. During training trials, after the subject had made his/her choice, the wall was removed and the figures' size became visible. The smaller figure was always $1 \mathrm{~cm}$ shorter than the taller one. Choices of the taller figure resulted in the addition of a symbolic coin to a pile. Choices of the smaller figure led to the loss of a coin. Top: name allocations to subject groups

shorter figure led to the loss of a coin, accompanied by a descending tone sequence. The names continued to be visible for $2 \mathrm{~s}$, and then the subjects could call up the next trial by pressing a middle key. In nonreinforced trials neither visual size nor acoustic feedback was given and the pile of coins was displayed unchanged. Each learning block consisted of 100 trials, in which each training pair was shown 10 times. The pairs were presented quasi-randomly throughout the experiment. Within the first five blocks all choices were reinforced. As soon as the subjects made fewer than $40 \%$ errors on each training pair, nonreinforced trials $(20 \%)$ were introduced. When choices within a given block involved less than $30 \%$ errors (binomial test; $p<.01$ ), the test phase followed.

During the test phase each of the 10 training pairs was presented 20 times and each of the 16 test pairs 10 times. The test pairs were classified according to their ordinal distance, i.e., the number of sequence items that separated the two stimuli that were shown paired.
The within-series test pairs included two pairs with the ordinal distance of 2 (BD, CE, bd, ce) and one pair with the distance of 3 (BE, be). For the between-series test pairs the analogous term ordinal separation is used. There were two test pairs with the separation $3(\mathrm{Be}, \mathrm{bE})$, four with the separation $2(\mathrm{Bd}, \mathrm{bD}, \mathrm{Ce}, \mathrm{cE})$, two with the separation $1(\mathrm{Cd}$, $\mathrm{cD})$ and two with the separation $0(\mathrm{Cc}, \mathrm{dD})$. During the test phase the training-pair trials always ended with pictorial feedback and reinforcement, the test pairs never. With test pairs the choice of the lesser ranking figure was recorded as an error. As this was not meaningful with the 0 -separation pairs, with them the choices of $c$ and D were arbitrarily recorded as errors. Altogether the test phase consisted of 360 trials, 160 of them being actual non-reinforced test trials.

Before the actual training, the subjects were told that they had to choose the taller figure in order to win a coin, that they would otherwise lose a coin, and that they could use the names of the figures to guide their choices. They were also informed that there would be occasional trials without feedback. After the session, the subjects were asked to complete a questionnaire, analogous to that used in the previous experiments. They were then presented with 12 cards bearing the names used during the experiment and were asked to order them according to height. If necessary, the subjects were subsequently shown the correct sequences, interviewed, and specifically asked whether they had recognized that there were two separate series. Finally they were told about the true purpose of the experiment.

Results

The subjects required between 200 and 700 trials (mean 420 ) to reach the learning criterion. The results for the training pairs and the within-series test pairs during the test phase are shown in Figure 7. The mean accuracies and latencies are shown averaged over the two independent transitivity series as there was only a slight difference between them (average differences in latencies $170 \mathrm{~ms}$, in error rates $2 \%$ points; Rao's $\mathrm{R}_{2,15}=3.90, p \approx .05$ ).

A statistical analysis of the within-series test-pair results reveals that the subjects generally chose transitively within each separate series. The error rates were well below chance level ( $\mathrm{t}$ tests; BD: $t_{19}=5.33, p<.0001$; bd: $t_{19}=3.45, p<.01$; CE: $t_{19}=3.55, p<.01$; ce: $t_{19}=3.29$, $p<.01$; BE: $t_{19}=4.09, p<.001$; be: $t_{19}=5.09, p<.0001$ ).

Thirteen of the 20 subjects qualified as solvers of the within-series transitivity tests by the criterion of fewer than $30 \%$ introduced earlier in this paper. All of them were also explicit, by the same criteria as in the previous experiments. The questionnaire answers indicated that all the subjects had clearly recognized the size-ordering principle. However, in some cases this explicit knowledge was obviously not enough to deal with the card task, as only 8 of the 13 explicit solvers could lay out both within-series sequences correctly. With one exception, the non-solving subjects also claimed to have relied on the size relations. Some of them said that they either had found it too hard to memorize all the confusing item names or had not made a sufficient effort to solve the test pairs.

Only seven subjects solved the between-series tests according to the criterion of less than $30 \%$ errors specified earlier. All seven had also solved the within-series tests. Figure 8, left, compares the mean accuracies and latencies of these subjects in both kinds of tests. The test-pair results are shown averaged according to their symbolic distance or symbolic separation. To the extent that the distances are 


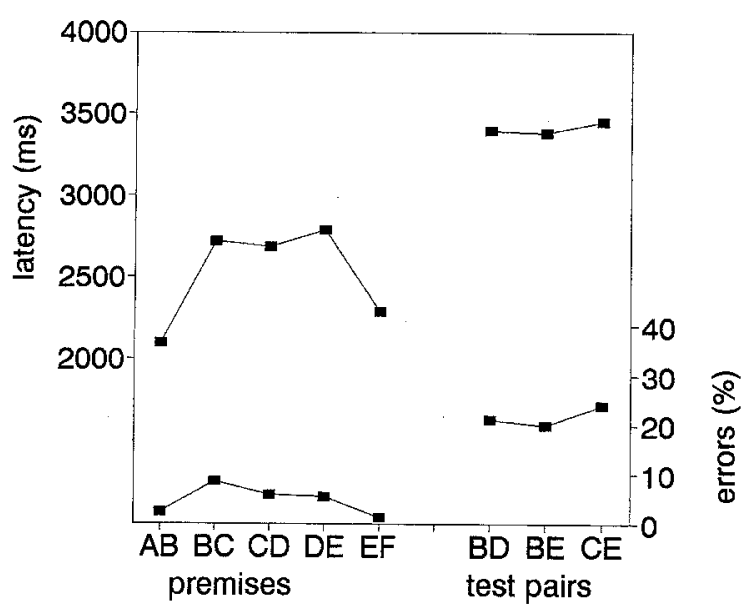

Fig. 7 Mean errors (\%) and mean latencies $(m s)$ for the premise pairs (left) and the within-series test pairs (right) during the test phase of Exp. $3(n=20)$. Results pertaining to both independent item series are errors shown pooled, using the A to $\mathrm{F}$ terminology

analogous, the response patterns are similar. The speed and accuracy improves with the ordinal separation of the between-series pairs. For comparison, Figure 8, right, presents the equivalent, solvers-only data obtained by Werner et al. (1992) with non-verbal shape stimuli. Except for the generally longer latencies obtained in our experiment, the differences are quite minor, although these authors, unlike us, used two perceptually quite distinct series composed of nameless curved and angular shapes, and also employed an abstract, pure conditioning task format.

The post-session enquiry provided some explanation for the relatively poorer performance on the between-series pairs compared with the within-series pairs. Only 5 (2 within-series-only test solvers and 3 both within- and between-series-test solvers) of the 13 subjects mentioned above were explicit about having recognized two separate item hierarchies during the experiment. Of the 8 subjects who laid out the cards at all correctly, only 5 laid the two series separately. The 3 other subjects laid out the series following one another. They had obviously construed a single series out of the two independent ones by concatenating them. This presumably led to a constant preference for the stimuli of one series over that of the other in the between-series tests. It may be relevant that the same subjects had made fewer errors with that particular series during the first block of premise-pair learning.

\section{Discussion}

The experiment examined transitive responding within and between two series of verbal items, in which the premises were presented as conditioning tasks. The performance on the training pairs is similar to that found with visual stimuli during Experiments 1 and 2, and specially during the closely comparable non-verbal experiment conducted by Werner et al. (1992). Reaction times and also error rates for training pairs during the test phase show the usual sym- bolic-position effect. Experiment 3 yielded generally longer reaction times, most likely as a consequence of the need to read the names of the stimulus items. Proportionally more subjects among the within-series solvers were explicit in the present experiment (13 out of 13) than in Werner et al.'s (1992) experiment (9 out of 13). It is remarkable, however, that six of the seven non-solver subjects, declared knowledge about the size relations that in principle should have enabled them to solve the within-series tests.

Between-series test-pair results revealed decreasing error rates and reaction rates with increasing ordinal separation of the stimuli. The subjects seemed to have resorted to two different strategies for a solution of these test pairs. Some subjects, much like those in Werner et al.'s (1992) experiment, behaved transitively towards between-series pairs, and thus seemed to choose according to conditioned-stimulus values. Other subjects attempted to integrate the two series into a single one and thus preferred to select the stimuli belonging to one of the series over those belonging to the other. They had erroneously represented both series as ordered one after the other.

None of the subjects, incidentally, behaved in accordance with the strict rules of formal logic. Such processing predicts consistent transitive choices within the series and truly chance choices between the series, since the two series were not bridged by any pair of premises and thus logically independent. But the development of between-series preferences agrees with what everyday experience demands. Meaningful choices between heterogeneous, strictly speaking unrelated, items are in fact indispensable - for example, when one has to choose between bananas and apples of varying qualities.

\section{General discussion}

Table 1 summarizes the key results of these three experiments and those of Werner et al.'s (1992) experiment. Since an effort was made to use closely comparable samples of subjects in all the experiments, restrained comparisons of their results are warranted. There was a planned increase in concreteness from Experiment 1 to Experiment 2, and similarly from Werner et al.'s (1992) experiment to Experiment 3. Experiment 1 employed abstract visual shapes with relations among them signalled only by reward and penalties. Subjects were comparatively slow in learning the pairs of premises and relatively few of those exhibiting transitive responding during tests revealed explicit knowledge. Experiment 2, though formally equivalent, used more realistic human figures that were additionally related through depicted social dominances. It yielded somewhat faster learning and a higher proportion of explicit-test solvers. Otherwise, however, both experiments yielded quite similar performance profiles (compare Figures 2 and 3). Werner et al.'s (1992) experiment in turn employed geometric-decorative shapes and a bare conditioning format, while Experiment 3, although structurally analogous to it, involved named human figures also related through obvious difference in size. Once more, premise acquisition 


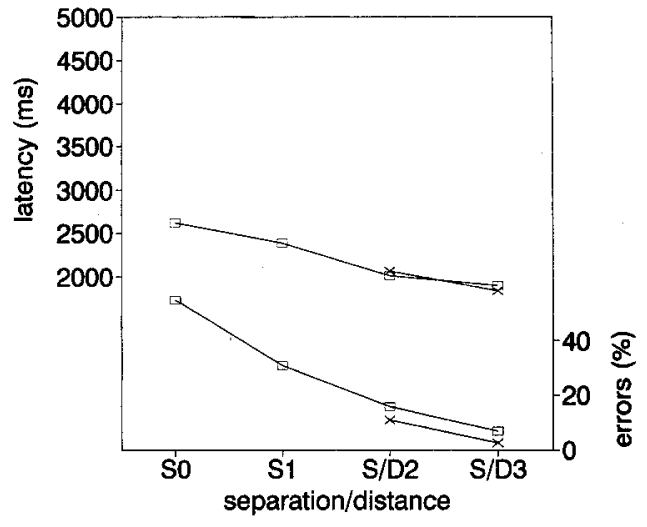

Fig. 8 Within-series ( $d$, item distance) and between-series ( $s$, item separation) test results of Exp. 3 with verbal stimuli ( $r i g h t ; n=7$ ). The analogous data from Werner et al. (1992) who used geometric-decorative stimuli $(l e f t ; n=11)$ is shown for comparison. Averages include only subjects who solved both the within- and the between-test pairs

was relatively faster and the proportion of explicit solvers was higher in Experiment 3 than in Werner et al.'s (1992) experiment. Otherwise, objective performance was again quite similar across Experiments 2 and 3, if one allows that the longer latencies of Experiment 3 were merely due to an additional name-identification time of some $1,500 \mathrm{~ms}$ (compare Figures 5 and 7).

Neither the variations in the surface formats employed, nor the differences in the implicitness and explicitness that arose as a result (significant when the data of the experiment pairs are combined: $\chi^{2}=6.11, d f=2, p<.05$ ) had much influence on the subjects' achievements in factual transitivity. This overall conclusion supports the inference already reached in connection with Experiment 1, where it was found that the objective performance of explicit- and implicit-test solvers were virtually identical (see also Siemann \& Delius, 1993; Werner et al., 1992). Thus all subjects seemed to have yielded transitive responses based upon an essentially implicit processing, regardless of whether they were subsequently able to produce explicit accounts of their behaviour.

This conjecture runs contrary to widespread opinion. Transitive responding, at least in so far as it is evinced by adults and older children, has in the past often been considered to be based on the explicit application of classical rules of logic (Clark, 1969; Hunter, 1957; Huttenlocher, 1968; Markovits \& Dumas, 1992; Piaget, 1921, 1965). Our subjects did not seem to resort to such rules. Several of the subjects who behaved transitively in Experiments 1 and 2 and also in Werner et al.'s (1992) experiment, could not provide an explanation for their test choices. If they had resorted to the rules of logic in the traditional sense, all test-pair solvers should have been able to report the procedures by which they attained transitivity. Furthermore, all the subjects who did reveal explicit knowledge about the syllogistic nature of the tasks performed no differently from those who did not. The results of Experiment 3, which used a format closely similar to the verbal syllogisms, were doubly revealing in this respect.

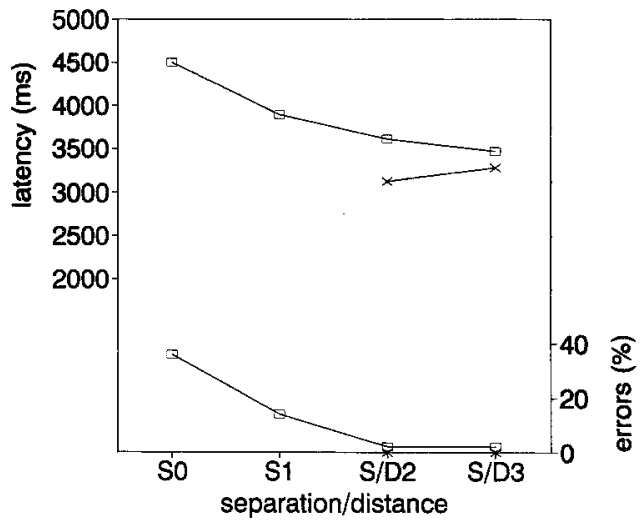

Several subjects, though aware of the logical structure within the separate series, did not draw the logically obvious conclusions when facing the corresponding tests. Other subjects in turn behaved against their declared rational insights by unlawfully showing transitive preferences among stimuli they recognized as belonging to two logically separate series. These findings, however, agree with the more modern view that even adult humans mostly do not follow the rules of logic when solving logical problems (Johnson-Laird, 1986; De Soto, London, \& Handel, 1965).

Several models that do not accord with logic rules can in fact explain transitive responding (Couvillion \& Bitterman, 1992; Harris \& McGonigle, 1994; Fersen et al., 1991; McGonigle \& Chalmers, 1977; Wynne, 1995). Werner et al. (1992) satisfactorily simulated the transitive responding of adult human subjects with a basic conditioning model (Luce, 1959; Wynne et al., 1992). Luce's model works on the principle that the response-controlling value of a given stimulus is modified by the reinforcement consequences arising from its choice on a given learning trial (see Appendix). However, as soon as the training pairs are responded to with reasonably good accuracy, Luce's model tends to predict excessively perfect transitive choices with test pairs. So this model cannot match the behaviour of the subjects who learn to deal correctly with the training pairs, but who do not perform much better than chance with the test pairs (the non-solvers). These individuals seem to learn much about the training pairs as differing configurations, but little about the single stimuli that form them.

The Appendix presents a modification of Luce's (1959) model that copes well with this circumstance. The $\varepsilon \kappa$ model assumes that a proportion of the value changes that take place during training do not attach to the elementary stimuli, but rather to the stimulus configurations. As is shown in the Appendix, simulations with this new conditioning model achieve better agreements with empirical transitive responding results than did the original Luce model. This suggests that conditioning processes of quite an elementary nature may be all that is behind the implicit processing that underlies transitive responding. This may be so, even when the surface structure of the task in question approaches that of a classical transitive-inference syllogism (Experiment 3, Appendix). The assumption that specific stimulus values control the test performances blurs the 
Table 1 Main results of Experiments 1,2, 3 and Werner et al.'s (1992) experiment. For the latter two experiments only the within-series data is presented

\begin{tabular}{lrrrr}
\hline & 1 & 2 & Werner & \multicolumn{1}{c}{3} \\
\hline No. of Subjects & 24 & 20 & 20 & 20 \\
Trials/pair to criterion & 79 & 43 & 61 & 42 \\
\% solvers & 62 & 75 & 65 & 65 \\
\% explicit solvers of all solv. & 53 & 80 & 69 & 100 \\
rt (ms) premises. (solv.) & 1491 & 1383 & 1423 & 2757 \\
rt (ms) tests (solv.) & 1830 & 1838 & 2007 & 3872 \\
$\%$ errors premises. (solv.) & 3 & 2 & 2 & 3 \\
\% errors tests (solv.) & 6 & 3 & 5 & 4 \\
\hline
\end{tabular}

distinction often made between transitive inferences and transitive choices. The latter refer to the consistent spontaneous preferences often found when a set of items is offered in varying combinations. The choices between such items (for example wine, beer, cider, coke, and water) are generally considered as being determined purely by utility values attached to the individual items (Bradbury \& Nelson, 1973; Zajonc, 1980). Transitive choices among stimuli, that signal the qualities, delays, or scheduling of reinforcement associated with them are of course also thought to depend on the values that have been conditioned upon them (Belke, 1992; Mazur \& Coe, 1987).

In our experiments the increasing concreteness of the stimuli and their relationships led to a mounting explicitness or awareness about the underlying logical structure of the tasks. However, this did not have any facilitating effect on the objective performance during transitivity tests. Indeed, within an experiment similar to the present Experiment 1 (Siemann, $1993 \mathrm{a}$; Siemann \& Gebhardt, 1996) a group of subjects was explicitly instructed beforehand that they had to begin by deducing the serial order of the stimulus items and then try to choose throughout according to this hierarchical order. The instructed, and thus of course explicit, solver subjects learned somewhat faster the training pairs, but their objective test performance (accuracy and latency profiles) was again indistinguishable from that of uninstructed solvers.

It is true that the validity of the distinction between implicit and explicit cognitions has been repeatedly disputed (Perruchet, Gallego, \& Pacteau, 1992; Shanks \& St. John, 1994). However, much of this dispute has been concerned with semantics, rather than with facts. The adoption of an operational definition seems the best way out. What should matter is whether the performance established with one task - here the successful solution of a nonverbal syllogism - transfers to another task, namely the production of a verbal account of the problem's structure that matches that solution. If such transfer does not occur, it is possible to say that only an implicit-task command is present; if the transfer does occur, it is appropriate to speak of an explicit-task knowledge. Veridical verbal accounts of only some properties - here often about the relations of the stimuli within training pairs - but not about the underlying stimulus hierarchy that is critical for the solution of transitivity tests, clearly do not qualify as explicit knowledge in any interesting sense. We also used an additional test of performance transfer - i.e., the production of stimulus sequences with cards. Several of our subjects were capable, albeit mostly only after some encouragement, of solving this task without having been able to verbalize the stimulus order. So performance transfer generally is not necessarily dependent on explicitness as was defined above, unless this definition is relaxed, so that one could then say that these subjects were in some sense half explicit. Indeed, it may be quite unrealistic to view the states of implicitness and explicitness as being sharply dichotomous. But we did adhere to a consistent criterion for implicitness and explicitness throughout our experiments.

Regardless of the difficulties with defining the terms unequivocally and universally (an issue that we do not pretend to have resolved), it is undeniable that the distinction between implicit and explicit processing has found increasing favour over recent years. Implicit performance, as somehow dissociated from verbalizable relevant awareness has been shown to be probable, and indeed common, in the context of several cognitive competences (Berry, 1991; Haan et al., 1987; Reber, 1989; Seeger, 1994; Schacter, 1987). This appears to conflict with what introspections appear to tell us. We seem prone to recall only those inferential events that we drew, or believe to have drawn, under conscious control; but in reality we are undoubtedly often forced to make fast and ready choices without much conscious deliberation. In most cases an evaluation of the circumstances, procedures, and consequences would be too time-consuming for any useful realtime decisions. Recent experimental evidence, for example, indicates that transitive inferences are increasingly implicit when subjects also cope with extra memory loads (Siemann, 1994a). The most likely account is that decisions are generally reached implicitly, even if we are inclined to remember episodically only those that we have reached explicitly. Perhaps the latter is the reason for the concept of implicit cognitions being so strenuously resisted.

It is not unlikely, moreover, that the evolution of a competence for transitive responding preceded the emergence of a capacity for awareness. As has already been mentioned, pigeons, rats, squirrel-monkeys, and chimpanzees are similarly successful in non-verbal inference tasks (Boysen et al., 1993; Chalmers \& McGonigle, 1984; Davis, 1992; Fersen et al., 1991; McGonigle \& Chalmers, 1992). Many animal species, including some phylogenetically basal ones, live in social groups characterized by dominance hierarchies. The survival and reproduction of members of such species is greatly influenced by how efficiently they cope with these dominance structures. Mistaken assessments often mean major losses, whereas correct decisions commonly lead to sizeable gains in fitness. Much field evidence indicates that individuals make use of knowledge about social hierarchies that most often are linear. Sometimes such information is exploited very ingeniously. Macaques, for instance, are known to divert cunningly attacks from a superior monkey to a bystander of lower rank that is also a friend and/or relative of the aggressor (Cheney, Seyfarth, \& Smuts, 1986; Waal, 1988; cf. Reber, 1993). 
Table 2 Percentage of correct choices for training and test pairs observed in Experiment $1(n=24)$ and predicted by Luce's model and the $\varepsilon \kappa$ model

\begin{tabular}{llllllllr}
\hline & $\mathrm{AB}$ & $\mathrm{BC}$ & $\mathrm{CD}$ & $\mathrm{DE}$ & $\mathrm{EF}$ & $\mathrm{BD}$ & $\mathrm{BE}$ & $\mathrm{CE}$ \\
\hline Luce's model & 98 & 96 & 95 & 92 & 99 & 100 & 100 & 100 \\
Observed & 98 & 97 & 95 & 91 & 99 & 80 & 77 & 66 \\
Eאmodel & 98 & 97 & 95 & 94 & 98 & 78 & 80 & 63 \\
\hline
\end{tabular}

Given the efficiency of implicit transitivity, what are, if any, the advantages of explicit transitivity? We believe that the answer lies again in the social context. Assuming linguistic competences, individuals who are able to transmit working knowledge about social hierarchies and strategies to their uninformed friends and relatives would be at an inclusive Darwinian fitness advantage vis-à-vis those who could not. The necessary verbalizations would be possible only if that knowledge were available explicitly. Thus, while implicit transitivity, coded as differentiated preferences for social partners, can be conceived as sufficient for the private domain, it has to be converted into explicit transitivity if it is to be shared through instruction with one's in-group partners (see also Mandler, 1989). That is not to deny that explicit knowledge may then also have come to play a role when transitivity tasks presented themselves verbally such as in "Anna is bigger than Mary," etc..

Naturally, these arguments have consequences for the already varied and controversial definitions of transitive inference. If one binds the definition of inference to language, reasoning, and awareness, then the competence is virtually denied to animals. Such a narrow definition, however, disregards the implicit human transitive behaviour amply demonstrated here. It is obvious that neither language, reasoning nor awareness are the necessary preconditions for valid conclusions that may often be the precursors of explicit insights about the relational structure of things. If the definition is relaxed then it has to be admitted that young children and animals also possess at least non-verbal transitive abilities. Regardless of how these semantic issues are settled, non-verbal and semi-verbal transitivity tasks of the type we have used here are likely to go on being heuristically useful tools in the comparative psychology of deductive reasoning.

\section{Appendix}

Luce model

In this conditioning model of transitive responding the associative, response eliciting value $V_{Z}$ of a given stimulus $Z$ is increased by a fraction determined by a factor $\beta_{+}$if the response to it is followed by a reward, and decreased by a fraction determined by a factor $\beta_{-}$if the choice of the stimulus is followed by a penalty. Given a trial with the stimulus pair $\mathrm{X}+\mathrm{Y}-$ (standing for any and all of the premise pairs of our design) and given the current probability $p_{x y}$ that stimulus $\mathrm{X}$ rather than stimulus $\mathrm{Y}$ will be chosen, then the mean effective value changes of the two stimuli, assuming that several subjects are taking part in the experiment, are given by the update equations $V_{X} \leftarrow V_{X}+$ $\left(\mathrm{V}_{\mathrm{x}} * \beta+* \mathrm{p}_{\mathrm{xy}}\right)$ for $\mathrm{X}$ and $\mathrm{V}_{\mathrm{y}} \leftarrow \mathrm{V}_{\mathrm{y}}-\left(\mathrm{V}_{\mathrm{y}} * \beta *\left(1-\mathrm{p}_{\mathrm{xy}}\right)\right.$ for $\mathrm{Y}$. The arrow $\leftarrow$ indicates that a left-hand variable takes the value of the right-hand expression. The choice probability controlling the next trial is then given by $p_{x y}=V_{x} /\left(V_{x}+V_{y}\right)$. These formulae can easily be turned into a computation algorithm with which specific transitivity experiments can be simulated (see Werner et al., 1992, for more details).

These simulations show that even though according to the usual design of a transitive responding experiment, the middle stimuli of the sequence (B, C, D, and E in our case) appear to be scheduled to be rewarded and penalized equally often, they actually are not. Consider first the stimulus pair $\mathrm{A}+\mathrm{B}-$. Because $\mathrm{A}$ is consistently rewarded, it is increasingly chosen as soon as discriminative learning begins to take effect. This means that $\mathrm{B}$ is decreasingly chosen and penalized. Thus facilitates rewarded choices of $\mathrm{B}$ in the B+C-pair. Soon choices of B are generally more often rewarded than penalized. Now consider pair E+F-. As $\mathrm{F}$ is consistently punished, $\mathrm{E}$ is increasingly chosen and rewarded. This favours penalized choices of $E$ in the $D+E-$ pair. Choices of $\mathrm{E}$ are therefore more evenly rewarded and punished than those of B. In associative value terms, stimulus $B$ can thus be seen as gaining from being paired with always rewarded $A$, and stimulus $E$ as loosing from being paired with always penalized $F$. The values of stimuli $\mathrm{C}$ and $\mathrm{D}$ take graded intermediate positions in the ensuing choice/reinforcement balancing process. The net effect of this reward/penalty ratio-biasing mechanism is that, according to the model, training with the premise pairs leads to a $V_{a}>V_{b}>V_{c}>V_{d}>V_{e}>V_{f}$ ranking of stimulus values. This value ranking process has some similarity with the idea that humans solve transitive inference tasks by recurring to an imaginary linear representation (mental line; cf. Trabasso \& Riley, 1975) of the items that they build up from the pairwise information contained in the premises.

As an example, the simulation of the present Experiment 1 involved 100 trials per training pair. The learning parameters $\beta_{+}=0.12$ and $\beta_{-}=0.55$ were found to yield the best fit for the empirical performance on the training pairs during test phase. The initial $\mathrm{V}$ magnitudes were all set to an identical small number. The stimulus values, averaged over the last 20 trials (test phase), yielded the percentage choice predictions $\left(\mathrm{p}_{\mathrm{xy}} * 100\right)$ listed in Table 2. Though in good agreement with performance of the training pairs the predictions somewhat overestimate the performance on the test pairs. To a lesser extent, this is even the case when only the performance of the solver subjects is considered (not shown).

EK model

The $\varepsilon \kappa$ model (Siemann, 1994b) can cope adequately, albeit at the cost of an additional free parameter, with this response pattern and is at the same time general enough to embody also something close to Luce's (1959) model as a 
possible variant. The model assumes that (rewarded) choices of the stimulus $X$, within a given pair $X+Y-$, cannot only lead to an increment of its value $V_{x}$, but also to a separate increment of a value $V_{x y}$ belonging to stimulus $X$ when configured with $Y$. Conversely (penalized) choices of the stimulus $\mathrm{Y}$ in a pair $\mathrm{X}+\mathrm{Y}-\mathrm{can}$ lead to a decrement of its value $V_{y}$ and also to a decrement of a value $V_{y x}$ belonging to stimulus $\mathrm{Y}$ when configured with $\mathrm{X}$.

The stimulus values $V_{x}$ and $V_{y}$ concerning the elementary stimuli $\mathrm{X}$ and $\mathrm{Y}$ are comparable to those occurring in Luce's model and their changes are basically determined by the same learning rate parameters $\beta_{+}$and $\beta_{-}$occurring in that model but modulated by a weighting parameter $\varepsilon$ (elementary) where $0 \leq \varepsilon \leq 1$. Thus, the choice of stimulus $X+$ with the probability $P_{x y}$ leads to a value update $V_{x} \leftarrow V_{x}+$ $\left(\mathrm{V}_{\mathrm{x}} * \beta+* p_{\mathrm{xy}} * \varepsilon\right)$ and alternatively, the choice of stimulus $\mathrm{Y}-$ with the probability $p_{y x}=1-p_{x y}$ leads to a value update $\mathrm{V}_{\mathrm{y}} \leftarrow \mathrm{V}_{\mathrm{y}}-\left(\mathrm{V}_{\mathrm{y}} * \beta_{-} *\left(1-\mathrm{p}_{\mathrm{xy}}\right) * \varepsilon\right)$. Naturally, these values that correspond to the elementary stimuli are also subject to analogous modifications when they are chosen in neighbouring training pairs (for example, $\mathrm{Y}$ in the $\mathrm{Y}+\mathrm{Z}-$ pair rather than in the $X+Y$ pair).

The stimulus values $V_{x y}$ and $V_{y x}$, accruing respectively to the stimulus configurations $\mathrm{X}$ with $\mathrm{Y}$ and $\mathrm{Y}$ with $\mathrm{X}$, are determined by the same learning parameters $\beta_{+}$and $\beta_{-}$but modulated by another weighting parameter $\kappa$ (configurational), where $\varepsilon+\kappa=1$. Accordingly the choice of stimulus $X+$ with probability $p_{x y}$ leads to a value update $V_{x y} \leftarrow V_{x y}+$ $\left(\mathrm{V}_{\mathrm{xy}} * \beta_{+} * p_{\mathrm{xy}} * \kappa\right)$ for the stimulus configuration $\mathrm{X}$ with $\mathrm{Y}$ and the choice of $Y$ - with probability $p_{y x}=1-p_{x y}$ leads to a value update $\mathrm{V}_{\mathrm{yx} \leftarrow}-\mathrm{V}_{\mathrm{yx}}-\left(\mathrm{V}_{\mathrm{yx}} * \beta_{-} *\left(1-\mathrm{p}_{\mathrm{xy}}\right) * \kappa\right)$ for the stimulus configuration $\mathrm{X}$ with $\mathrm{Y}$. Obviously, these particular conditional values do not change when one of the component stimuli is chosen from within a neighbouring training configuration (e.g., again $\mathrm{Y}$ in the $\mathrm{Y}+\mathrm{Z}$ - pair rather than in the $\mathrm{X}+\mathrm{Y}-$ pair).

The choice probabilities governing the stimulus choices in the next $\mathrm{X}+\mathrm{Y}-$ trial are determined by the configural value $V_{x y}$ of stimulus $X$ with $Y$ multiplied with the elementary value $V_{x}$ of stimulus $X$, and similarly the configural value $V_{y x}$ of stimulus $Y$ with $X$ multiplied with the elementary value $V_{y}$ of stimulus $Y$ according to $\mathrm{W}_{\mathrm{x}}=\mathrm{V}_{\mathrm{x}} * \mathrm{~V}_{\mathrm{xy}}$ and $\mathrm{W}_{\mathrm{y}}=\mathrm{V}_{\mathrm{y}} * \mathrm{~V}_{\mathrm{yx}}$. The probability $p_{\mathrm{xy}}$ of a choice of stimulus $\mathrm{X}$ in the presence of $\mathrm{Y}$ is then $p_{\mathrm{xy}}=\mathrm{W}_{\mathrm{x}} /$ $\left(\mathrm{W}_{\mathrm{x}}+\mathrm{W}_{\mathrm{y}}\right)$. The probability $p_{\mathrm{qz}}$ of choosing stimulus $\mathrm{Q}$ in non-adjacent test pairs QZ is determined solely by the elementary stimulus values $\mathrm{V}_{\mathrm{q}}$ and $\mathrm{V}_{\mathrm{z}}$ according to $p_{\mathrm{qz}}=\mathrm{V}_{\mathrm{q}} /\left(\mathrm{V}_{\mathrm{q}}+\mathrm{V}_{\mathrm{z}}\right)$, since potential configural values $\mathrm{V}_{\mathrm{qz}}$ and $\mathrm{V}_{\mathrm{zq}}$ cannot play any significant role as stimuli $\mathrm{Q}$ and $\mathrm{Z}$ were not presented together during training and thus nothing may have been learned about the QZ configuration.

It is easy to see that choice probabilities relevant during tests depend on the values of the weighting parameters $\varepsilon$ and $\kappa$ operating during learning. With $\varepsilon=1$ and $\kappa=0$, the elementary stimulus values $V_{x}$ and $V_{y}$ change, but not the configurational stimulus values $\mathrm{V}_{\mathrm{xy}}$ and $\mathrm{V}_{\mathrm{yx}}$. The $\varepsilon \kappa$-model behaves then almost identically to Luce's model yielding transitive responding with test pairs. If $\kappa=1$ and $\varepsilon=0$ the model yields a purely configurational type of learning that produces correct choices with training pairs, but not with test pairs. The ratio between the parameters $\kappa$ and $\varepsilon$ can be conceived of as describing how the different individual subjects (and by extension, how much weight the representative average subject of a population) give(s) to the stimulus pair configurations on the one side and to the elementary stimuli that constitute them on the other side. As shown in Table 2, a simulation of Experiment 1, following the same principles as before, but with an intermediate version of the $\varepsilon \kappa$ model with the weighting parameters $\varepsilon=0.65$ and $\kappa=0.35$ as well as the learning parameters $\beta_{+}=0.04$ and $\beta=0.25$ in fact yielded a better fit to the empirical choice data of all subjects than Luce's model (tests observed vs. predicted; Luce's model, 20.9, $d f=7, p<.01 ; \varepsilon \kappa$-model, $0.41, d f=7, p>.05$ ).

The model, with suitably adjusted parameters, achieves comparable matches with the results of Experiments 2 and 3 , except those of the between-series tests of the latter experiment where the $\varepsilon \kappa$ model still overstimates transitive choices and still needs additional modifications.

Acknowledgements This research was supported by the Deutsche Forschungsgesellschaft. We thank Professor J. Emmerton (Purdue) for critical comments, G. Latini (Konstanz) and C. Roberts (Exeter) for language improvements. J. D. D. is grateful to Dr. J. M. Findlay for sabbatical hospitality at the Department of Psychology, University of Durham (England).

\section{References}

Attneave, A. (1956). The quantitative study of shape and pattern perception. Psychological Bulletin, 53, 452-471.

Belke, T. W. (1992). Stimulus preference and the transitivity of preference. Animal Learning \& Behavior, 20, 401-406.

Bentall, R. P., Dickins, D. W., \& Fox, S. R. A. (1993). Naming and equivalence: Response latencies for emergent relations. Quarterly Journal of Experimental Psychology, 46B, 187-214.

Berry, D. C. (1991). The role of action in implicit learning. Quarterly Journal of Experimental Psychology, 43A, 881-906.

Boysen, S. T., Berntson, G. G., Shreyer, T. A., \& Quigley, K. S. (1993). Processing of ordinarily and transitivity by chimpanzees (Pan troglodytes). Journal of Comparative Psychology, 107, 208-215.

Bradbury, H., \& Nelson, T. M. (1973). Transitivity and the patterns of adult preferences. Bulletin of the Psychonomic Society, 1, $337-339$.

Bryant, P. E., \& Trabasso, T. (1971). Transitive inferences and memory in young children. Nature, 232, 456-458.

Chalmers, M., \& McGonigle, B. O. (1984). Are children any more logical than monkeys on the five-term series problem? Journal of Experimental Pedagogy, 5, 68-77 and 121-127.

Cheney, D., Seyfarth, R., \& Smuts, B. (1986). Social relationships and social cognition in nonhuman primates. Science, 234, 1361-1366.

Clark, H. H. (1969). Influence of language on solving three-term series problems. Journal of Experimental Psychology, 82, 205-215.

Couvillion, P. A., \& Bitterman, M. E. (1992). A conventional conditioning analysis of "transitive inference" in pigeons. Journal of Experimental Psychology: Animal Behavior Processes, 18, $308-310$.

Davis, H. (1992). Logical transitivity in animals. In W. K. Honig \& J. G. Fetterman (Eds.). Cognitive aspects of stimulus control (pp. 405-429) Hillsdale: Erlbaum.

De Soto, C. B., London, M., \& Handel, S. (1965). Social reasoning and spatial paralogic. Journal of Personality and Social Psychology, 2, $513-521$. 
Fersen, L. von, Wynne, C. D. L., Delius, J. D., \& Staddon, J. E. R. (1991). Transitive inference formation in pigeons. Journal of Experimental Psychology: Animal Behavior Processes, 17, $334-341$

Gellermann, L. W. (1933). Chance orders of alternating stimuli in visual discrimination experiments. Journal of Genetic Psychology, 42, 206-208.

Gigerenzer, G., \& Hoffrage, U. (1995). How to improve baysian reasoning without instruction: frequency formats? Psychological Review, 102, 684-703.

Gillan, D. J. (1981). Reasoning in the chimpanzee: II. Transitive inference. Journal of Experimental Psychology: Animal Behavior Processes, 7, 150-164.

Haan, E. H. F. de, Young, A., \& Newcombe, F. (1987). Face recognition without awareness. Cognitive Neuropsychology, 4, 385-415.

Harris, M. R., \& McGonigle, B. O. (1994). A model of transitive choice. Quarterly Joumal of Experimental Psychology, 47B, $319-348$.

Hunter, I. M. L. (1957). The solving of three-term series problems. British Journal of Psychology, 48, 286-298.

Huttenlocher, J. (1968). Constructing spatial images: a strategy in reasoning. Psychological Review, 75, 550-560.

Johnson-Laird, P. N. (1986). Reasoning without logic. In T. Myers, K. Brown, \& B. McGonigle (Eds.) Reasoning and discourse processes (pp. 13-49). London: Academic Press.

Kuno, H., Kitadate, T., \& Iwamoto, T. (1994). Formation of transitivity in conditional matching to sample by pigeons. Journal of the Experimental Analysis of Behavior, 62, 399-408.

Luce, R. D. (1959). Individual choice behavior. New York: John Wiley.

Mandler, G. (1989). Memory: Conscious and unconscious. In Solomon, P. C., Goethals, G. R., Kelley, C. M., \& Stephens, B. R. (Eds.) Memory: Interdisciplinary approaches (pp. 84-106). New York: Springer Verlag.

Markovits, H., \& Dumas, C. (1992). Can pigeons really make transitive inferences? Journal of Experimental Psychology: Animal Behavior Processes, $18,311-312$.

Mazur, J. E., \& Coe, D. (1987). Tests of transitivity in choices between fixed and variable reinforcer delays. Joumal of the Experimental Analysis of Behavior, 47, 287-297.

McIntire, K. D., Cleary, J. P., \& Thompson, T. (1987). Conditional relations by monkeys: Reflexivity, symmetry, and transitivity. Journal of the Experimental Analysis of Behavior, 47, 279-285.

McGonigle, B., \& Chalmers, M. (1977). Are monkeys logical? Nature, 267, 694-697.

McGonigle, B., \& Chalmers, M. (1992). Monkeys are rational? Quarterly Journal of Experimental Psychology, 45B, 189-228.

Mühlherr, A., \& Siemann, M. (1995). Transitive inferences in young children: Testing a child-suitable learning setting. In N. Elsner \& R. Menzel. Learning and memory (p. 34). Stuttgart: Thieme.

Perruchet, P., Gallego, J., \& Pacteau, C. (1992). A reinterpretation of some earlier evidence for abstractiveness of implicitly acquired knowledge. Quarterly Journal of Experimental Psychology, 44A, $193-210$.

Piaget, J. (1921). Une forme verbal de la comparison chez l'enfant [A verbal form of comparisons in children]. Archives de Psychologie, 1921, 141-172.

Piaget, J. (1965). Logic and psychology. Manchester: University Press.

Reber, A. S. (1989). Implicit learning of artificial grammars. Journal of Verbal Learning and Verbal Behavior, 77, 317-327.

Reber, A. S. (1993). Implicit learning and tacit knowledge. Oxford: Clarendon Press.
Schacter, D. L. (1987). Implicit memory: History and current status. Journal of Experimental Psychology: Learning, Memory, Cognition, $13,501-518$.

Seeger, C. A. (1994). Implicit learning. Psychological Bulletin, 115 , $163-196$.

Shanks, D. R., \& St. John. M. F. (1994). Characteristics of dissociable human learning systems. Behavioral and Brain Sciences, 17, $367-447$.

Sidman, M. (1990) Equivalence relations: Where do they come from? In D. E. Blackman \& H. Lejeune (Eds.). Behaviour analysis in theory and practice: Contributions and controversies (pp. 93-114) Hove: Lawrence Erlbaum.

Siemann, M. (1993a). Transitive Inferenz: Experimentelle Untersuchung einer kognitiven Leistung [Transitive inference: experimental investigation of a cognitive competence]. $\mathrm{Ph}$. D. Dissertation, Universität Konstanz.

Siemann, M. (1993b). "Transitive inferences" in pigeons and humans In N. Elsner \& M. Heisenberg (Eds.). Gene, brain, behavior (pp. 857). Stuttgart: Thieme.

Siemann, M. (1994 a). Memory load influences on transitive responding in humans. In N. Elsner \& H. Breer (Eds.). Sensory transduction (p. 847). Stuttgart: Thieme.

Siemann, M. (1994b). Überprüfung einfacher Modelle zum transitiven Schlußfolgern bei nonverbaler Aufgabenform [Test of simple models of transitive inference using a nonverbal form of presentation]. Zeitschrift fiir experimentelle und angewandte Psychologie, 41, 584-616.

Siemann, M., \& Gebhardt, R. P. (1996). Einfluss der Instruktion und Aufgabenkomplexität auf transitive Schlußfolgerungen (Influence of instructions and task complexity upon transitive deductions) (Submitted)

Siemann, M. \& Delius, J. D. (1993). Implicit deductive responding in humans. Naturwissenschaften, 80, 363-366.

Siemann, M., \& Delius, J. D. (1994). Processing of hierarchic stimulus structures has advantages in humans and animals. Biological Cybernetics, 71, 531-536.

Siemann, M., Delius, J. D,, \& Wright, A. A. (1994). Transitive responding in pigeons: Influence of stimulus frequency and reinforcement history. Behavioural processes, in press.

Sperber, D., Cara, F., \& Girotto, V. (1995). Relevance theory explains the selection task. Cognition, 57, 31-95.

Trabasso, T., \& Riley, C. A. (1975). The construction and use of representation involving linear order. In R. L. Solso (Ed.) Information processing and cognition. The Loyola symposium (pp. 381-410). New York: Erlbaum.

Waal, F. de (1988). Chimpanzee politics. In R. Byrne \& A. Whitten (Eds.) Machiavellian intelligence (pp. 122-131). Oxford: Clarendon Press.

Werner, U., Köppl, U., \& Delius, J. D. (1992). Transitive Inferenz bei nichtverbaler Aufgabendarbietung [Transitive inference with nonverbally presented tasks]. Zeitschrift für experimentelle und angewandte Psychologie, 39, 662-683.

Wynne, C. D. L. (1995). Reinforcement accounts for transitive inference performance. Animal Learning \& Behavior, 23, 207-217.

Wynne, C. D. L., Fersen, L. von, Staddon, J. E. R. (1992). Pigeons' transitive inferences are the outcome of elementary conditioning principles: a response. Journal of Experimental Psychology: Animal Behavior Processes, 18, 313-315.

Zajonc, R. B. (1980). Feeling and thinking. Preferences need no inferences. American Psychologist, 35, 151-175. 